\title{
Editorial preface to the Eugene Garfield Memorial Issue
}

\author{
W. Glänzel ${ }^{1}$ A. Schubert ${ }^{2} \cdot$ T. Braun ${ }^{2}$
}

Received: 10 January 2018/Published online: 20 January 2018

(C) Akadémiai Kiadó, Budapest, Hungary 2018

The link between Eugene Garfield and the journal Scientometrics goes back to more than 40 years, that is, way before the launching of the journal. In 1976, two years before the actual launching, the late Imre Ruff, Tibor Braun's fellow Professor of Chemistry and pioneer of scientometrics in Hungary, invited Garfield to act as Co-Editor-in-Chief. He welcomed and willingly accepted the invitation together with the three other invitees (see Fig. 1 and also Braun et al. 2010).

From this time on, he served the journal, later-until his last day-as Honorary Editor.

In a sense, we could say that our whole journal, its existence and identity, is a commemoration of Eugene Garfield, but after his passing away-as a part of the "grief work" - we felt the necessity of dedicating a special issue to his memory.

In this issue, a somewhat heterogeneous mixture of personal recollections and research articles inspired by or dedicated to the memory of Eugene Garfield are presented. Invited authors ranged from awardees of the Derek de Solla Price Medal through coworkers of Eugene Garfield and Editorial Board members of Scientometrics to the awardees of the Eugene Garfield Research Fellowship.

In this preface, we should like to avoid the usual "inventory" of contributions. The Editors are grateful to all contributors for accepting the invitation and submitting valuable input.

Memorial Issues are always sad occasions for casting an account. Our loss is immense but we also should gain impetus to do our work even more consciously and responsibly failing to have Eugene Garfield's watchful eye on us.

W. Glänzel

Wolfgang.Glanzel@kuleuven.be

1 ECOOM and Dept. MSI, KU Leuven, Leuven, Belgium

2 Hungarian Academy of Sciences, Budapest, Hungary 
EUGENE GARFIELD, Ph.D.

Chairman and President

December 21, 1976

I. Ruff, Ph.D., D,Sc./Chemistry

Akadémiai Kiads

Alkotmány Utca 21 .

H-1054 Budapest

HUNGARY

Dear Dr. Ruff:

I am very happy to accept youn inyitation to be one of the editors-in-chief with Professons D. deSolla-Price, V. V,

Nalimov and G. M. Dobrov of the new journal SCIENTOMETRICS.

The idea of an international joumnal which will publish papers on quantitative aspects of science of science and science policy

is a good one. There are not many journals where researchers in these areas can publish their results quickly and have a broad readership.

The editorial board is a very distinguished one, and I am sure that with their help, the journal will be able to oublish high quality papers. Please keep me intormed of progress in the development of the new journal, and what ways you wish me to participate.

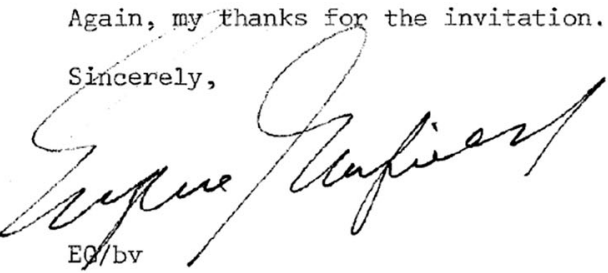

Fig. 1 Eugene Garfield's letter of acceptance to the invitation to act as Editor-in-Chief of the journal Scientometrics (Reproduced from the journal's correspondence archive)

\section{Reference}

Braun, T., Glänzel, W., \& Schubert, A. (2010). The footmarks of Eugene Garfield in the journal Scientometrics. Annals of Library and Information Studies, 57(3), 177-183. 